\title{
Laryngeal Cancer Attributable Factors and the Influence on Survival Rates: A Single Brazilian Institution Experience
}

\author{
Lara Maria Alencar Ramos Innocentini ${ }^{1 \oplus}$ Alisson Henrique Teixeira ${ }^{2}$ Luciana Assirati Casemiro ${ }^{3}$ \\ Matheus Carrijo Andrade ${ }^{2}$ Tatiane Cristina Ferrari ${ }^{1}$ Hilton Marcos Alves Ricz ${ }^{4}$ Leandro Dorigan de Macedo ${ }^{1}$ \\ ${ }^{1}$ Dentistry and Stomatology Division, Ophthalmology, \\ Otolaryngology and Head and Neck Surgery Department, Hospital \\ das Clínicas da Faculdade de Medicina de Ribeirão Preto, \\ Universidade de São Paulo, Ribeirão Preto, SP, Brazil \\ 2 Department of Oral Medicine, Faculdade de Odontologia da \\ Universidade de Franca, Franca, SP, Brazil

\begin{abstract}
Address for correspondence Lara Maria Alencar Ramos Innocentini, Dentistry and Stomatology Division, Ophthalmology, Otolaryngology and Head and Neck Surgery Department, Hospital das Clínicas da Faculdade de Medicina de Ribeirão Preto, Universidade de São Paulo, Avenida Bandeirantes, 3900, Monte Alegre, Ribeirão Preto, SP, 14040160551636022863 , Brazil (e-mail: linnocentini@usp.br).
\end{abstract}

${ }^{3}$ Department of Oral Rehabilitation, Universidade de Franca, Franca, SP, Brazil

${ }^{4}$ Ophthalmology, Otolaryngology and Head and Neck Surgery Department, Hospital das Clínicas da Faculdade de Medicina de Ribeirão Preto, Universidade de São Paulo, Ribeirão Preto, SP, Brazil

Int Arch Otorhinolaryngol 2019;23:e299-e304.

\begin{abstract}
Keywords

- cancer of the larynx

- smoke

- alcohol drinking

- survival analysis

Introduction Epidemiological studies focused on prognostic factors associated with laryngeal cancer in the Brazilian population are poorly reported in the literature.

Objective To evaluate the influence of certain risk factors on the survival rates of patients with squamous cell carcinoma (SCC) of the larynx.

Methods This retrospective study was conducted on adult patients who were admitted to the outpatient clinic of the head and neck department in a tertiary care hospital. Evaluation of the influence of risk factors on the survival rates of patients registered in the hospital with laryngeal SCC was performed based on age, sex, initial stage, time of evolution, habits, educational levels and relapse and death. Overall survival (OS), disease-free survival (DFS) and clinical-demographic data were analyzed using the Kaplan-Meier method, Log-rank test and Cox regression.

Results A total of 107 patients with a mean age of 59.8 years (range 19-81) were included in this study. Stages III and IV were associated with decreased DFS $(p=0.02)$ and OS $(p=0.02)$. Smoking patients had a greater period of disease evolution than non-smoking patients $(p=0.003)$. Alcohol consumption in smokers increased the risk of death by $2.8(p=0.002)$ compared with non-drinking smokers. Male patients presented lower DFS average when compared with female patients $(p=0.04)$.

Conclusion Our study confirms that male gender, smoking habit combined with alcohol consumption, and advanced stages were strongly associated with poor prognosis.
\end{abstract}

\section{Introduction}

Malignant tumors of the upper aerodigestive tract are a leading cause of death worldwide. Of these, laryngeal cancer

(1) Lara Maria Alencar Ramos Innocentini's ORCID is https://orcid. org/0000-0002-9899-5178.
(LC) seems to occur more commonly in men than in women (6.310 vs 0.930 estimated new cases in 2018, respectively), according to the data for the state of São Paulo, Brazil. ${ }^{1,2}$ Most of these tumors are squamous cells carcinoma (SCC) and $\sim 60 \%$ of the patients present advanced (stage III or IV) disease at diagnosis. ${ }^{3}$ Unfortunately, LC is one of a few received

October 18, 2018

accepted after revision

March 12, 2019
DOI https://doi.org/

10.1055/s-0039-1687909. ISSN 1809-9777.
Copyright $\odot 2019$ by Thieme Publicações License terms Ltda, Rio de Janeiro, Brazil 
oncologic diseases in which the 5-year survival rate has decreased over the past 40 years, from 66 to $63 \%$, although the overall incidence is declining. ${ }^{1}$ Recently, a study showed that most of LC included in the global burden was found in high socioeconomic countries before 2010 and now has shifted toward low socioeconomic countries. ${ }^{4}$

Several risk factors are associated with LC, although tobacco smoke and alcohol consumption are the most significant ${ }^{2,5-7}$ Survival rates are multifactorial, and many factors have been considered in population studies, such as anatomical subsite, comorbidity, and more recently, tumors testing positive for human papillomavirus (HPV) in LC patients. ${ }^{6,8,9}$ Currently, a study showed $63.9 \%$ of 5 -year overall survival (OS) and $72.3 \%$ of disease-free survival (DFS) for LC patients. ${ }^{10}$ Above all, it seems pertinent to remember that factors such as, older age, low educational level, delay in diagnosis, and delay in referral of the patients with voice changes to otolaryngologists or head and neck surgeons are strongly unfavorable for prognosis. ${ }^{8,9}$

Considering the importance of clinical-demographic data in the incidence of LC, there is little information about their influence on disease prognosis. Therefore, epidemiological data present in literature clearly shows the need for more information about the impact of these risk factors in LC prognosis. This study presents our results of descriptive epidemiology of LCs, with a special focus on risk factors and prognosis influence on OS and DFS of the laryngeal SCC.

\section{Materials and Methods}

\section{Study Design and Patient Population}

Following approval from the Hospital Committee for Research Involving Human Subjects (n. 12104/2011), a retrospective review of the patients referred to head and neck oncology was performed. We analyzed one hundred and seven patients' records with the diagnosis code of LC at the head and neck referral service over a period of 22 years (1984-2006). The inclusion criteria were patients over 18 years old diagnosed with SCC of the larynx, while the excluding criteria were previous history of tumor, doubt about primary tumor origin and/or occult primary tumor, previous cancer therapy and any other disease that can interfere in the natural oncology course.

All information regarding age, gender, initial stage, time of evolution, habits, educational levels, relapse and death were collected, included and analyzed in this study. Habits analysis was performed considering the number of cigarettes per day, duration of habit and duration without the habit. The consumption of alcohol was analyzed, taking into consideration type, quantity per day, time duration of consumption, and time duration without drinking. Gender, age, stage, educational level and time of evolution were compared in terms of OS and DFS.

\section{Statistical Analysis}

Habits analysis was performed in two stages. At first, the interference of the presence of the habit (smoking, drinking, and smoking and drinking together) was investigated with regard to the survival of the patient, for which the log-rank test was applied to the Kaplan-Meier curve. Secondly, the Cox Regression test was applied to the gross value of daily consumption and duration of habit.

Information relating the stage was inserted after judicious evaluation, intending to reduce its influence on the final results. The TNM classification of malignant tumors (TNM) evaluation was performed based on the Union for International Cancer Control (UICC) classification. ${ }^{11}$

The survival interval was a period of time from the diagnosis of LC to death. Disease status was assessed using clinical criteria at last follow-up. Kaplan-Meier analysis was performed using the SPSS statistical package software Version 17.0; (SPSS Inc., Chicago, IL, USA) with log-rank testing for assessment of survival outcomes. Risk factor analysis was performed using the Spearman rank correlation coefficient, and the 2-tailed $t$-test for comparison of demographic data. Statistical significance was considered at $p$ value $<0.05$. The Cox Regression test was applied to all variables.

\section{Results}

\section{Descriptive Epidemiology}

- Table 1 shows the clinical demographic data of all patients included in this study. Males were predominant in this group of patients (80.3\%), with a mean age of 59.8 years (range 1981 years). Patient habits like smoking (91\%) and drinking (56\%), with several cigarettes smoked per day and a habit duration between 30 and 50 years and alcohol consumption of $1 \mathrm{~L}$ of beverages a day for at least 30 years were found to be the most prevalent habits associated with LC. Due to lack of data, the smoking habit was evaluated in 103 patients. The median of LC evolution reported by non-smoking patients was 2 months; therefore, patients with smoking habits presented 4 months of LC evolution in median. This difference was statistically significant when both groups were compared $(p=0.01)$.

The most frequent complaints associated with the onset of symptoms for LC were dysphonia and dysphagia. Regarding the time of evolution, up to 6 months was presented in $58 \%$ of the patients and more than 6 months in 37\%. Stages I and II represented $49 \%$ of the patients, and stages III and IV corresponded to $51 \%$. Regarding educational, $12 \%$ of the subjects were illiterate, $71 \%$ completed elementary education, $12 \%$ completed high school, and there was no data available for $5 \%$.

\section{Survival}

For variables such as, age, gender, educational level and evolution time, analyzed with the log-rank test, no statistical significance was found for OS. Advanced stage (III and IV) were the only variable with a decrease in OS $(p=0.02)$. Gender presented a significant difference $(p=0.04)$ only in DFS, in which males presented a worse prognosis. Advanced stage (III and IV) presented a decreased rate in DFS as well $(p=0.02$ ). Nevertheless, evolution time was not significant $(p=0.05)$ (-Table 2). Advanced stages were associated with a significant increase in the risk of disease recurrence (83\%) and death (68\%) in a 5 -year period. 
Table 1 Clinical-demographic data of laryngeal cancer patients

\begin{tabular}{|c|c|c|}
\hline \multicolumn{2}{|l|}{ Variable } & Number (\%) \\
\hline \multicolumn{3}{|l|}{ Age (years) } \\
\hline \multicolumn{2}{|l|}{ Average } & 59.80 \\
\hline \multicolumn{2}{|l|}{ Median } & 61.00 \\
\hline \multicolumn{2}{|l|}{ SD } & $10.246(19-81)$ \\
\hline \multicolumn{3}{|l|}{ Gender } \\
\hline \multicolumn{2}{|l|}{ Male } & $86(80.3)$ \\
\hline \multicolumn{2}{|l|}{ Female } & $14(13.08)$ \\
\hline Smokers & & $94(91)$ \\
\hline \multirow{3}{*}{ Amount/day $\left(2-60^{*}\right)$} & 10 & 6.5 \\
\hline & 20 & $43.0 \%$ \\
\hline & 40 & $6.5 \%$ \\
\hline \multirow[t]{3}{*}{ Time (years) $\left(1-70^{*}\right)$} & 30 & $8.4 \%$ \\
\hline & 40 & $7.5 \%$ \\
\hline & 50 & $8.4 \%$ \\
\hline Total & & $103^{\ddagger}$ \\
\hline Drink consumption (Beverages) & & $60(56)$ \\
\hline Amount (ml/day) & 100 & $5.6 \%$ \\
\hline \multirow[t]{2}{*}{$\left(50-1000^{*}\right)$} & 200 & $6.5 \%$ \\
\hline & 1000 & $8.4 \%$ \\
\hline Time (years) & 30 & $7.4 \%$ \\
\hline \multirow[t]{2}{*}{$\left(5-55^{*}\right)$} & 40 & $2.8 \%$ \\
\hline & 50 & $2.8 \%$ \\
\hline Total & & $107^{\dagger}$ \\
\hline
\end{tabular}

Abbreviations: SD, standard deviation; WI, without information.

'Variation found in patients' charts.

'Total number of cases studied.

†Total cases with data for evaluation of the variable.
The COX regression considering variables like habits, stages and gender showed male sex, smokers+drinkers and advanced stages with higher risk of disease relapse in a 5-year period. Patients that only smoke presented decreased risk of death $(\mathrm{OR}=0.19 ; p=0.001)$, and there was a 2.85 times increased risk of death for drinkers associated with smoking habit as well. Despite the strong trend no significant difference in OS was observed for advanced stages.

For DFS, smokers without drinking decreased risk of death in $68 \%(\mathrm{OR}=0.32 ; p=0.01)$ and advanced stage increased it by 1.83 times, in the period evaluated (-Table $\mathbf{3}$ ). Surgery was better therapy employed for prognosis in both OS and DFS ( $p=0.001)$ and $(p=0.005)$, respectively ( - Table 4$)$.

Kaplan-Meier plots with the analyses comparing habits, stages and gender (log-rank and Cox regression tests) are shown (-Fig. 1).

\section{Discussion}

Registration of SCC of the larynx in population databases varies between regions and countries and can be under-registered if the country has problems in notification of cases, as it happens in Brazil. The most frequent complaints associated with the onset of symptoms for larynx disease were dysphonia and dysphagia. Usually, patients with these complaints were referred by primary care physicians to a head and neck surgeon. In this scenario, high-risk patients with voice changes must be evaluated by these professionals, intending early diagnosis and treatment of LC. ${ }^{9}$ However, most of the cases (51\%) in this study of 107 patients presented advanced stages of disease at diagnosis, which remains a concern for public health. These data bring awareness about the need of more public politics for LC early diagnosis.

In this study, factors related to the number of cigarettes smoked and alcohol intake, habit duration and abstinence time did not interfere with the evolution of the disease studied. However, the presence or absence of smoke habit demonstrate differences in disease progression, with a faster manifestation

Table 2 Age, sex, stage, educational level and evolution time in survival rates of laryngeal cancer patients (Log rank test)

\begin{tabular}{|c|c|c|c|c|c|c|c|c|c|}
\hline \multirow[t]{2}{*}{ Variable } & & \multicolumn{3}{|c|}{ Overall survival } & \multirow[b]{2}{*}{$P$} & \multicolumn{3}{|c|}{ Disease-free survival } & \multirow[b]{2}{*}{$P$} \\
\hline & & $\mathbf{S}^{*}$ & SE & $95 \% \mathrm{Cl}$ & & $\mathbf{S}^{*}$ & SE & $95 \% \mathrm{Cl}$ & \\
\hline \multirow[t]{2}{*}{ Age } & Until 60 & 37.23 & 3.44 & $30.48-43.98$ & \multirow[t]{2}{*}{0.39} & 27.48 & 3.65 & $20.32-34.63$ & \multirow[t]{2}{*}{0.09} \\
\hline & Above 60 & 54.76 & 4.54 & $45.85-63.66$ & & 41.37 & 5.42 & $30.75-51.98$ & \\
\hline \multirow[t]{2}{*}{ Gender } & Male & 49.52 & 3.61 & $42.44-56.61$ & \multirow[t]{2}{*}{0.17} & 34.13 & 4.15 & $26.06-42.19$ & \multirow[t]{2}{*}{0.04} \\
\hline & Female & 47.40 & 6.38 & $34.89-59.91$ & & 42.66 & 6.66 & $29.60-55.73$ & \\
\hline \multirow[t]{2}{*}{ Stage } & $I+I I$ & 60.15 & 4.32 & $51.68-68.63$ & \multirow[t]{2}{*}{0.02} & 45.15 & 5.32 & $34.72-55.57$ & \multirow[t]{2}{*}{0.02} \\
\hline & III + IV & 34.05 & 3.45 & $27.28-40.81$ & & 24.43 & 3.49 & $17.59-31.27$ & \\
\hline \multirow[t]{3}{*}{ Educational level } & None & 37.58 & 6.63 & $22.04-48.72$ & \multirow[t]{3}{*}{0.59} & 35.38 & 6.80 & $22.04-48.72$ & \multirow[t]{3}{*}{0.84} \\
\hline & 1 & 54.94 & 3.92 & $32.95-49.06$ & & 41.01 & 4.11 & $32.95-49.06$ & \\
\hline & 2 & 36.84 & 6.44 & $16.58-45.10$ & & 30.84 & 7.27 & $16.58-45.10$ & \\
\hline \multirow[t]{2}{*}{ Time of evolution } & $<6 \mathrm{~m}$ & 38.26 & 3.13 & $32.12-44.40$ & \multirow[t]{2}{*}{0.07} & 29.23 & 3.29 & $22.76-35.69$ & \multirow[t]{2}{*}{0.05} \\
\hline & $>6 \mathrm{~m}$ & 59.75 & 5.25 & $70.06-49.44$ & & 51.25 & 5.52 & $40.42-62.07$ & \\
\hline
\end{tabular}

Abbreviations: S*, survival; SE, standard error; $\mathrm{Cl}$, confidence interval. Bold number are statistically significant values. 
e302 Risk Factors for Laryngeal Cancer in Brazil Ramos Innocentini et al.

Table 3 Multivariate Cox regression analysis of laryngeal cancer patients

\begin{tabular}{|l|l|l|l|l|}
\hline & \multicolumn{2}{|l|}{ Overall survival } & Disease-free survival \\
\hline Factors & OR (95\% Cl) & $P$-value $^{*}$ & OR (95\% Cl) & $P$-value \\
\hline Gender (male) & - & - & $2.64(1.05-6.65)$ & $\mathbf{0 . 0 4}$ \\
\hline Only Smokers & $0.19(0.08-0.48)$ & $<\mathbf{0 . 0 0 1}$ & $0.32(0.13-0.77)$ & $\mathbf{0 . 0 1}$ \\
\hline Drinkers + Smokers & $2.85(1.50-5.42)$ & $\mathbf{0 . 0 0 1}$ & - & - \\
\hline Stage (III + IV) & $1.68(0.94-2.92)$ & 0.08 & $1.83(1.11-3.04)$ & $\mathbf{0 . 0 2}$ \\
\hline
\end{tabular}

Abbreviations: $\mathrm{Cl}$, confidence interval; OR, odds ratio.

${ }^{*}$ Cox proportional hazards model.

Table 4 Survival at 5 years after treatment employed for laryngeal cancer patients

\begin{tabular}{|l|l|l|l|l|l|l|}
\hline & \multicolumn{2}{|l|}{ Overall Survival } & \multicolumn{2}{l|}{ Disease-Free Survival } \\
\hline Factors & $\begin{array}{l}\text { AS (months) } \\
\text { A less B }\end{array}$ & \multicolumn{2}{l|}{ Final results } & $\begin{array}{l}\text { AS (months) } \\
\text { A less B }\end{array}$ & \multicolumn{2}{l|}{ Final results } \\
\hline & & $\mathrm{X}^{2}$ & $P$ & & $\mathrm{X}^{2}$ & $P$ \\
\hline Su. X WSu. & +31.98 & 10.81 & $\mathbf{0 . 0 0 1}$ & +20.52 & 8.01 & 0.005 \\
\hline R X WR & -14.34 & 0.17 & 0.68 & -11.35 & 1.23 & 0.25 \\
\hline Ch X WCh & -22.91 & 3.20 & 0.08 & -18.80 & 3.10 & 0.08 \\
\hline
\end{tabular}

Abbreviations: AS, average survival; Ch, chemotherapy; R, radiotherapy; Su, surgery; WCh, without chemotherapy; WR, without radiotherapy; WSu, without surgery. Bold number are statistically significant values.

of disease in non-smoking patients. Recent epidemiological studies reinforce the influence of tobacco smoking and alcohol consumption as major risk factors for laryngeal carcinoma. ${ }^{8,12}$ Considering the amount of tobacco smoked in a day, Zuo et $\mathrm{al}^{8}$ showed, in their meta-analysis of observational studies, that subjects who smoked for 40 or more years have 5 times more risk than subjects who never smoked. Most of our subjects smoked 20 cigarettes a day in a period between 30 and 50 years. In addition, smokers with lower risk of relapse and death in a 5-year period when compared with non-smokers, as we showed (only 4 in this study), could be explained by genetic and molecular alterations considered as a distinct pathological entity and leading to poor prognosis; thus, this fact needs more investigation. $^{13,14}$ Complementary, in the literature, more relapses are observed in smokers as genetic alterations remains in patients, even after quitting the habit, and the presence of concept of field cancerization in these subjects is very important ${ }^{15,16}$ Another factor is that most of the smokers do not quit the habit, which increases the rate of second primaries and decreases the OS. Thus, a key of primary prevention is cessation of smoking habit for head and neck cancer. $^{17,18}$

In regard to socioeconomic status (SES) and survival, some studies do indeed show an influence on prognosis, although this effect is lost after accounting for other factors like age, gender, TNM stage, smoking/alcohol. ${ }^{17}$ Our study shows just $12 \%$ of subjects with high school completed, but no evaluation about per capita income was performed. Literature shows that a lower SES is associated with greater smoking and alcohol consumption, comorbidity, and advanced stages, ${ }^{9}$ therefore this population clearly needs more education. ${ }^{18,19}$ Therefore, is relevant to consider that a lower educational level is connected with delayed diagnosis and poor self-care. Moreover, results from a recent research provide compelling evidence in support of low educational level as unfavorable prognostic factor for $\mathrm{LC}^{10}$

Standard treatments available for LC are surgery, radiotherapy and chemotherapy. ${ }^{19}$ From the data available, surgery appears to be the method that is likely to result in the best chance of a cure, ${ }^{20}$ especially if there is the possibility of receiving adjuvant treatment postoperatively. ${ }^{21}$ Surgery is the first treatment of choice in early stages of LC and is considered more suitable for this stage. In advanced stages, surgery is selected only for selected cases. ${ }^{22}$ Studies have been shown that prognosis is better when surgery is the first modality of choice. ${ }^{22,23}$ After surgery, the rehabilitation and survival of these patients are difficult issues. In this moment it is quite important to consider patient's quality of life, mainly in regard to vocal rehabilitation for patients who undergone total laryngectomy. In the last years, tracheoesophageal prosthesis (TEP) is considered the best option for voice rehabilitation, even when compared with esophageal and electrolarynx speech. ${ }^{16}$ However, some patients with advanced LC and surgery indication desire organ preservation protocols even if it portends a worse outcome.

Considering this was not a prospective, regimented, or randomized trial this study limitations should be different treatment protocols received. This diversity was expected because of long period of data collection. Nevertheless, most of the patients were treated with surgery, which is considered the fastest therapy available for our institution and it is consistent with literature recommendations ${ }^{22}$ which 


\section{Overall Survival}
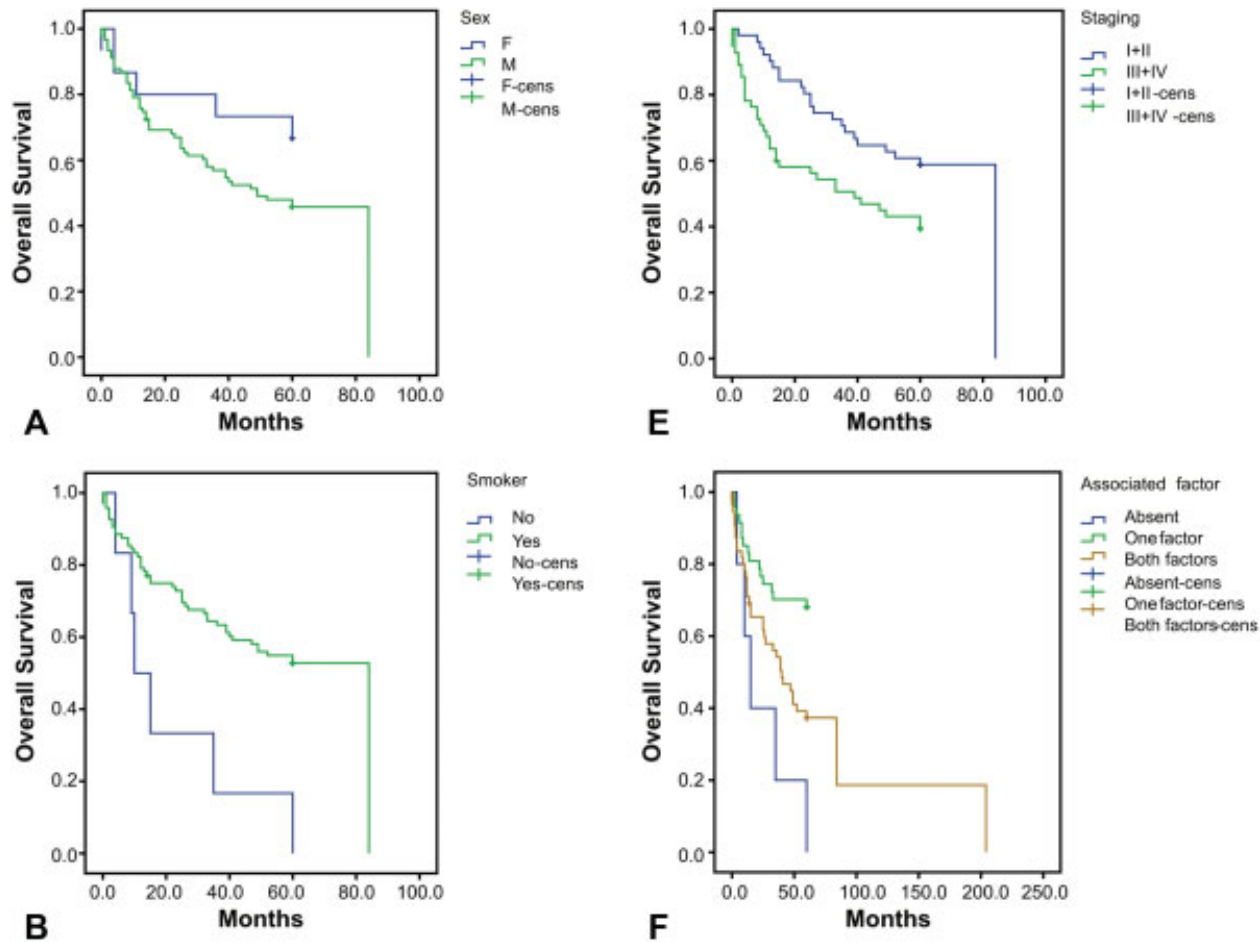

\section{Disease-free survival}
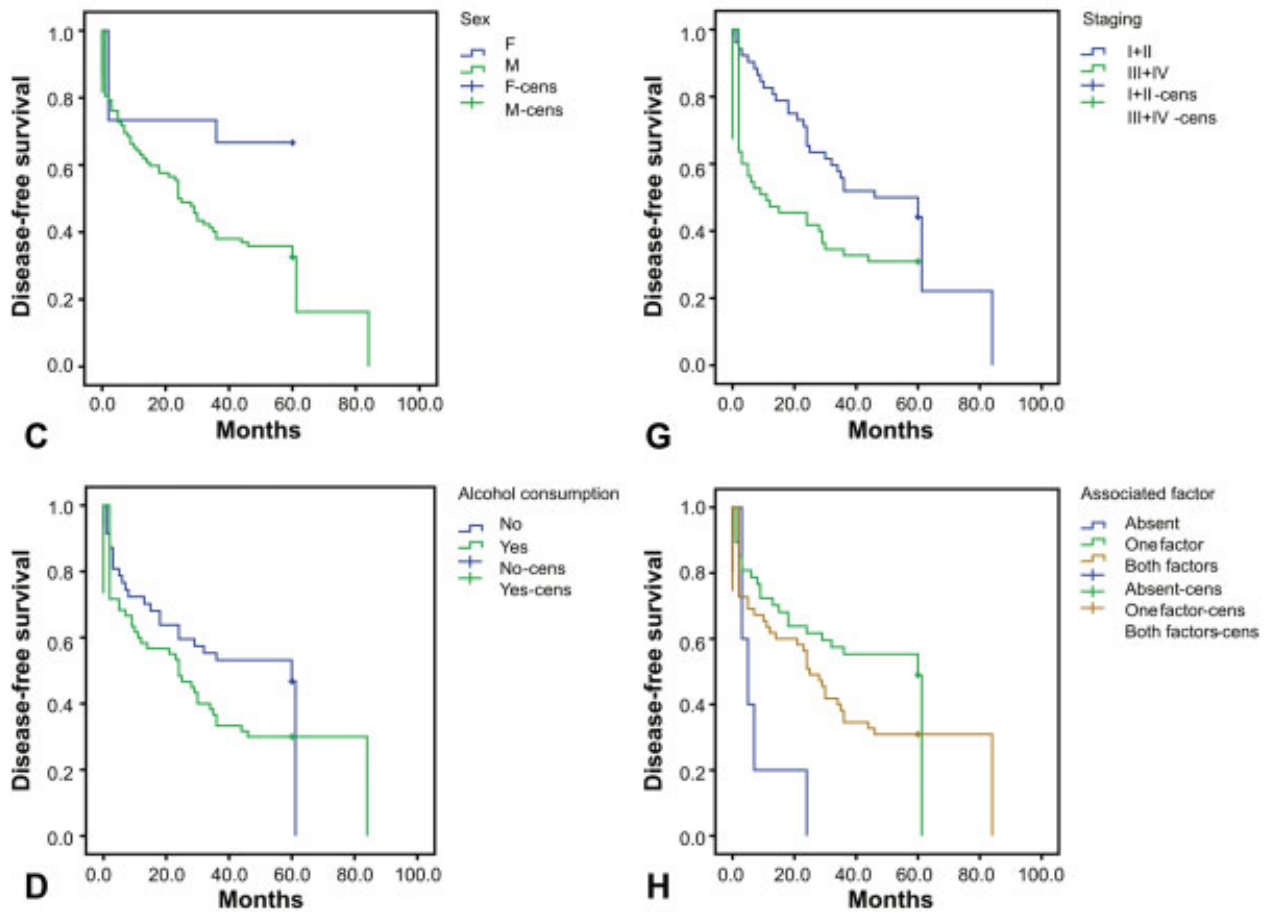

Fig. 1 Kaplan-Meier plots of overall and disease-free survival (Log-Rank and Cox-regression test), (A) and (C) Comparing male gender versus female gender, with decreased overall survival (OS) and disease-free survival (DFS) for men, and statistical significance for DFS ( $p=0.04)$; (E) and (G) comparing stages I + II versus stages III + IV, showed no significant decrease OS $(p=0.08)$ and significant DFS $(p=0.02)$ for advanced stages (III + IV); (B) comparing smokers versus non-smokers (without habit) that presented decreased OS $(p=0.003) ;(F)$ and $(H)$ comparing absence of habits versus both factors (smoker and drinking) versus one habit (only smokers) show significant difference among the three condition, with the worst results for non-habits OS $(p=0.001)$ and DFS $(p=0.005)$; (D) comparing alcohol consumption versus no alcohol consumption, results showed decreased DFS for alcoholic $(p=0.002)$. 
implies in a better prognosis. After considering the therapies employed and the final prognosis, further studies reported significant outcome benefit in OS of patients with T4a and stage IV LC who underwent total laryngectomy. ${ }^{14,16}$ Despite the limitations of this study this is the first study in Brazilian population to show impact of tobacco, alcohol and advanced stages in survival of LC patients. All the patients still benefited from formal multidisciplinary treatment planning. Thereby, further studies with larger groups and longer follow-up periods are needed to perform a more accurate evaluation of these risk factors for LC and its impact on prognosis.

\section{Conclusion}

In conclusion, this study revealed that the stage of disease and positive history of alcohol consumption can affect the survival rate of the patient. As the stage of disease is associated with survival of LC, it seems beneficial to encourage people to do screening. Additionally, public health politics focused on population education about these risk factors and access to enhanced medical services for early diagnosis and treatment have to be encouraged to improve the survival rates.

Conflicts of Interest

The authors declare no conflicts of interest.

\section{References}

1 Siegel RL, Miller KD, Jemal A. Cancer statistics, 2016. CA Cancer J Clin 2016;66(01):7-30

2 Instituto Nacional do Câncer. Estimativa 2018 para neoplasia maligna da laringe [Internet]. Neoplasia maligna da laringe. 2018 [cited 2018 Feb 10]. Available from: http://www1.inca. gov.br/estimativa/2018/mapa-laringe.asp

3 Groome PA, O'Sullivan B, Irish JC, et al. Management and outcome differences in supraglottic cancer between Ontario, Canada, and the Surveillance, Epidemiology, and End Results areas of the United States. J Clin Oncol 2003;21(03):496-505

4 Ramsey T, Guo E, Svider PF, et al. Laryngeal cancer: Global socioeconomic trends in disease burden and smoking habits. Laryngoscope 2018;128(09):2039-2053

5 Gama RR, Carvalho AL, Longatto Filho A, et al. Detection of human papillomavirus in laryngeal squamous cell carcinoma: Systematic review and meta-analysis. Laryngoscope 2016;126(04):885-893

6 Kuper H, Boffetta P, Adami HO. Tobacco use and cancer causation: association by tumour type. J Intern Med 2002;252(03):206-224

7 Boffetta P, Hashibe M. Alcohol and cancer. Lancet Oncol 2006;7 (02):149-156
8 Zuo J-J, Tao Z-Z, Chen C, et al. Characteristics of cigarette smoking without alcohol consumption and laryngeal cancer: overall and time-risk relation. A meta-analysis of observational studies. Eur Arch Oto-Rhino-Laryngology 2016;274(03):1617-1631

9 Chu KP, Habbous S, Kuang Q et al. Socioeconomic status, human papillomavirus, and overall survival in head and neck squamous cell carcinomas in Toronto, Canada. Cancer Epidemiol 2016; 40:102-112

10 Giraldi L, Leoncini E, Pastorino R, et al. Alcohol and cigarette consumption predict mortality in patients with head and neck cancer: a pooled analysis within the International Head and Neck Cancer Epidemiology (INHANCE) Consortium. Ann Oncol 2017;28 (11):2843-2851

11 Patel SG, Shah JP. TNM staging of cancers of the head and neck: striving for uniformity among diversity. CA Cancer J Clin 2005;55 (04):242-258; quiz 261-262, 264

12 Jayalekshmi PA, Nandakumar A, Akiba S, Gangadharan P, Koriyama C. Associations of tobacco use and alcohol drinking with laryngeal and hypopharyngeal cancer risks among men in Karunagappally, Kerala, India -Karunagappally cohort study. PLoS One 2013;8(08):e73716

13 Smith MM, Abrol A, Gardner GM. Assessing delays in laryngeal cancer treatment. Laryngoscope 2016;126(07):1612-1615

14 Merten JW, Parker A, Williams A, King JL, Largo-Wight E, Osmani M. Cancer Risk Factor Knowledge Among Young Adults. J Cancer Educ 2016;32(04):865-870

15 Bhatia A, Burtness B. Novel Molecular Targets for Chemoprevention in Malignancies of the Head and Neck. Cancers (Basel) 2017;9 (09):113

16 Ryser MD, Lee WT, Ready NE, Leder KZ, Foo J. Quantifying the Dynamics of Field Cancerization in Tobacco-Related Head and Neck Cancer: A Multiscale Modeling Approach. Cancer Res 2016; 76(24):7078-7088

17 McCarter K, Martínez Ú, Britton B, et al. Smoking cessation care among patients with head and neck cancer: a systematic review. BMJ Open 2016;6(09):e012296

18 Sampson L, Papadakos J, Milne V, et al. Preferences for the Provision of Smoking Cessation Education Among Cancer Patients. J Cancer Educ 2018;33(01):7-11

19 Wick CC, Rezaee RP, Wang T, et al. Use of concurrent chemoradiation in advanced staged (T4) laryngeal cancer. Am J Otolaryngol 2016;38(01):72-76

20 Jayaram SC, Muzaffar SJ, Ahmed I, Dhanda J, Paleri V, Mehanna H. Efficacy, outcomes, and complication rates of different surgical and nonsurgical treatment modalities for recurrent/residual oropharyngeal carcinoma: A systematic review and meta-analysis. Head Neck 2016;38(12):1855-1861

21 Zafereo ME, Hanasono MM, Rosenthal DI, et al. The role of salvage surgery in patients with recurrent squamous cell carcinoma of the oropharynx. Cancer 2009;115(24):5723-5733

22 Timme DW, Jonnalagadda S, Patel R, Rao K, Robbins KT. Treatment Selection for T3/T4a Laryngeal Cancer: Chemoradiation Versus Primary Surgery. Ann Otol Rhinol Laryngol 2015;124(11):845-851

23 Megwalu UC, Sikora AG. Survival outcomes in advanced laryngeal cancer. JAMA Otolaryngol Head Neck Surg 2014;140(09): 855-860 